\title{
Evaluating the Association of State Regulation of Community Health Workers on Adoption of Standard Roles, Skills, and Qualities by Employers in Select States: A Mixed Methods Study
}

\section{Tammie M. Jones ( $\nabla$ tjones48@gmu.edu )}

George Mason University College of Health and Human Services https://orcid.org/0000-0001-8761-2015

Alex Schulte

George Mason University College of Health and Human Services

\section{Suhashini Ramanathan}

George Mason University College of Health and Human Services

\section{Meron Assefa}

George Mason University College of Health and Human Services

\section{Srilatha Rebala}

George Mason University College of Health and Human Services

\section{Peggy J. Maddox}

George Mason University College of Health and Human Services

\section{Research Article}

Keywords: Community health worker, workforce, state regulation, certification, core competencies

Posted Date: May 7th, 2021

DOI: https://doi.org/10.21203/rs.3.rs-491630/v1

License: (c) (i) This work is licensed under a Creative Commons Attribution 4.0 International License. Read Full License

Version of Record: A version of this preprint was published at Human Resources for Health on December 1st, 2021. See the published version at https://doi.org/10.1186/s12960-021-00684-y. 


\section{Abstract}

\section{Background}

The occupation of Community Health Worker (CHW) has evolved to support community member navigation of complex health and social systems. The U.S. Bureau of Labor Statistics formally recognized the occupation of Community Health Worker (CHW) in 2009. Since then, various national and state level efforts to professionalize the occupation have been undertaken. The Community Health Workers Core Consensus (C3) project released a set of CHW roles and competency recommendations meant to provide evidence-based standards for $\mathrm{CHW}$ roles across work settings. Some states have adopted the recommendations, however, there are a variety of approaches regarding the regulation of the occupation. As of 2020, 19 U.S. states have implemented voluntary statewide CHW certification programs. The purpose of this study was to explore the relationship between state regulation of CHWs and adoption of standard roles, skills, and qualities by employers in select states.

\section{Methods}

This mixed methods study used purposive sampling of job ads for CHWs posted by employers from 2017-2020 in select states. Natural language processing was used to extract content from job ads and preprocess the data for statistical analysis. ANOVA, chi-square analysis, and MANOVA was used to test hypotheses related to the relationship between state regulation of $\mathrm{CHWs}$ and differences in skills, roles, and qualities employers seek based seniority of state regulatory processes and employer types.

\section{Results}

We observe that the mean job ads with nationally identified roles $(F(6,80549)=109.43, p=0.000)$, skills $(F(6,80549)=$ $136.13, p=0.000)$, and qualities $(F(6,80549)=257.29, p=0.000)$ included varies significantly between individual states, by state type, and by employer type.

\section{Conclusions}

Employment of $\mathrm{CHWs}$ is increasing as a means to provide culturally competent care, address the social determinants of health, and improve access to health and social services for members of traditionally underserved communities. Employers in states with $\mathrm{CHW}$ certification programs were associated with greater adoption of occupational standards set by state and professional organizations. Wide adoption of such standards may improve recognition of the $\mathrm{CHW}$ workforce as a valuable resource in addressing the needs of marginalized and difficult to serve groups.

\section{Background}

\section{History of Community Health Workers}

In recent years, efforts have evolved to professionalize the occupation by defining standardized core competencies, skills, and performance qualities. The U.S. Department of Labor (DoL) formally recognized CHWs as a distinct occupation by creating a standard occupational classification for the field in 2009.(1) Other national and state level efforts have also emerged to professionalize the occupation. The American Public Health Association defines $\mathrm{CHWs}$ as "frontline public health workers who are trusted members of and/or have an unusually close understanding of the community served. This trusting relationship enables $\mathrm{CHWs}$ to serve as a liaison or intermediary between health/social services and the community to facilitate access to services and improve the quality and cultural competence of service delivery." The Community Health Worker Core Consensus (C3) project released a set of CHW roles and competency 
recommendations meant to provide those working in the field and those outside the field with a set of evidence-based standards to evaluate CHWs' work across employment settings. Some states have adopted the recommendations, however, there remains wide variation in state's approaches toward regulating the occupation.

In order to understand the adoption and evolution of CHW's and the occupation's professionalization, we sought to understand whether employers in states with and without regulation of the occupation were more likely to adopt C3 recommended roles, skills, and qualities in job ads for $\mathrm{CHWs}$. The purpose of this study was to determine whether there is a relationship between state occupational regulation (i.e., certifications) and roles, skills, and qualities required by employers of community health workers.

\section{Growth of the CHW Workforce}

The Bureau of Labor Statistics projects the number of CHWs to grow 13 percent nationally from 2019 to 2029.(3) As of May 2020, the DoL reported that there were about 59,000 CHWs in the United States.(4) This number is likely underreported due to the range of titles $\mathrm{CHWs}$ go by. Other sources estimate the number of $\mathrm{CHWs}$ in the United States to be closer to $100,000 .(5)$

Several key policy changes have contributed to the growth in the CHW workforce. In 2010, the Affordable Care Act specifically listed $\mathrm{CHWs}$ as health professionals who function as members of health care teams and mandated additional navigation and coordination support, increasing the opportunity for CHWs. In addition, changes to federal Medicaid rules in 2013 opened the door for potential reimbursement for preventive services offered by CHWs.(1) Some examples of funding programs that states have implemented include Medicaid 1115 waivers, state Managed Care Contracts (MCOs), and/or State Plan Amendments (SPAs) to financially support the work of CHWs. These funding mechanisms have allowed state Medicaid offices to change how they organize, pay for, and incentivize health plans and providers that serve low-income or vulnerable patient populations.(6) In recent years, the CDC supported CHW programs through the State Public Health Actions to Prevent and Control Diabetes, Heart Disease, Obesity and Associated Risk Factors and Promote School Health grant (7) and more recently through COVID-19 Prevention and Control funding.(8)

National leaders have called for increased involvement of CHWs in the healthcare system, both as part of the COVID response and as a longer-term strategy to build a strong public health foundation.(9) Health plans are employing $\mathrm{CHWs}$ to address high costs from frequent-flyers or super-utilizers, and self-insured employers are employing $\mathrm{CHWs}$ for their health promotion and prevention programs to keep people healthy and on the job. Hospitals and health systems are using $\mathrm{CHWs}$ for proactive community engagement and post-acute care coordination to reduce 30-day readmissions and uncompensated care costs. Clinics and other outpatient offices are using CHWs to manage high-need chronic care patients and improve physician and nursing productivity.(10)

Across these settings, employers report integrating CHWs into multidisciplinary teams as a means to address pressing public health and healthcare needs, including improving service access and quality while reducing cost due to unnecessary utilization of services. Current literature is repleat with articles citing the value and/or impact of CHW' on improving chronic disease outcomes,(11-15) increasing access to health care services, $(16,17)$ reducing unnecessary hospitalizations.(18-22), and overall add value to healthcare systems.(23,24) According to a Biden campaign analysis of studies on CHW programs, such roles may produce an annual return of $\$ 2.47$ for every dollar invested from the perspective of a Medicaid payer.(25) 
Their knowledge, shared life experiences, trust-based relationships built on trust enable CHWs to address root causes of health issues in ways traditional systems often fall short (due to lack of time, cultural competence, and/or community linkages).(26) Continued growth in demand for $\mathrm{CHWs}$ will be driven by business models demonstrating success, policies that influence the evolution and expansion of $\mathrm{CHW}$ roles, standardization of the skills needed, and improved quality of jobs and career paths available to $\mathrm{CHWs}$.

\section{CHW Regulation}

There has been a shift towards increased state regulation, specifically certification, of the CHW occupation to ensure standardization and quality of the role, due to growth in employment and new/different types of organizations employing CHWs.(1) As of 2020, 19 U.S. states have implemented voluntary statewide CHW certification programs. Certification is seen as a mechanism to build a workforce with a common set of core skills, abilities, knowledge base, and training, signaling competency to employers, payers, and other members of health care teams.(27)

$\mathrm{CHW}$ certification is a specific form of credentialing related to recognizing an agreed-upon set of occupational standards, with certification itself often being voluntary. Broader occupational credentialing options also include licensure, registration, and permitting. To our knowledge, no states are exploring licensure for $\mathrm{CHWs}$ because $\mathrm{CHWs}$ do not perform clinical duties requiring a license and $\mathrm{CHW}$ practice does not pose a significant risk of harm to the public. $(28,29)$

Key benefits of certification include legitimizing the role of $\mathrm{CHWs}$ and ensuring consistency in the quality of care provided, conferring opportunities for educational and career advancement, improving employment stability, assuring that CHWs have a standard skillset and knowledge base, and increasing funding for services. $(30,31)$ Key factors many states cite as rationale for instituting a $\mathrm{CHW}$ certification process include establishing a reliable indicator or definition of $\mathrm{CHW}$ qualifications, gaining recognition for $\mathrm{CHWs}$ as an occupation or profession, and/or meeting reimbursement requirements.(28) $\mathrm{CHW}$ certification may provide the necessary support context to enable successful $\mathrm{CHW}$ programs within the larger healthcare system,(27) although there is lacking evidence regarding the relationship between certification and quality of care or patient outcomes.(32)

Although certification has several benefits, there are risks that certification and increased regulation may lead to narrow or rigid scopes of practice and over-medicalization of the field, undermining the community-centric orientation that often make CHWs so successful. In addition, there is a risk that certification processes could exclude people who may naturally be very effective $\mathrm{CHWs}$ but are turned away by regulatory criteria serving as barriers to entry and due to cost.

\section{State Differences in CHW Certification}

Although there are no national certification standards, C3 offers a single set of roles, skills, and qualities that are endorsed by major national stakeholder groups and is meant to be used by states as they develop the requirements for $\mathrm{CHW}$ certification. In spite of the C3 standards, there is variation in how state regulation and certification programs are carried out.(33) Key differences in CHW programs across states include the maturity of the program, type of certifying organization (i.e., public or private), entity certified, and cost of certification. The requirements for $\mathrm{CHW}$ certification include specific competencies (e.g., roles, skills, and qualities) that must be met. Some differences in select state $\mathrm{CHW}$ programs are displayed in Table 1.

Table 1 Differences in CHW Regulation Across Select States 


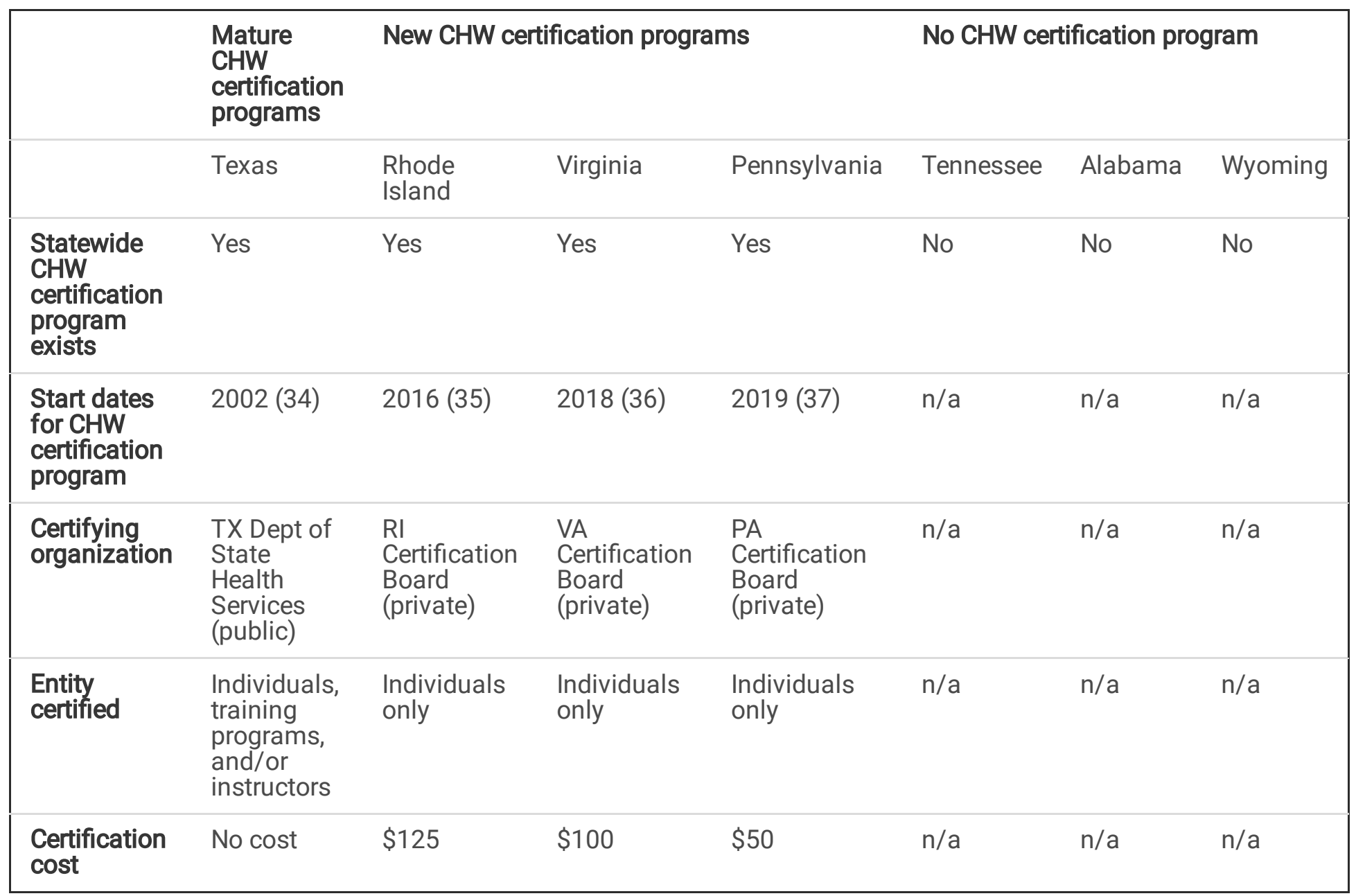

In states that have been certifying $\mathrm{CHWs}$ for a longer period of time and have more mature regulatory programs, we expect to see increased standardization in job competencies. The results of adoption of such standardization are expected to be seen in in the job ads from employers as they recruit for a consistent workforce that meets established competencies and quality standards.

\section{Methods}

The study was conducted in three phases: qualitative interviews, Natural Language Processing (NLP) and main analysis. The first phase included semi-structured interviews with nine subject matter experts on CHWs. The experts included representatives from a state-level $\mathrm{CHW}$ program manager, a $\mathrm{CHW}$ certifying organization, a state $\mathrm{CHW}$ association, a Medicaid managed care $\mathrm{CHW}$ program director, and a chair of a state level $\mathrm{CHW}$ council, to name a few. Input from these experts provided insights that helped shape this study.

The second phase, NLP, included extracting jobs ads and analyzing the text content of ads. Job ad data were obtained from Chmura, a company based in Richmond, Virginia that provides proprietary labor market software and data that collects job ads daily using Real-Time Intelligence. From the Chmura dataset we retrieved 134,844 job ads from 20172020 for employers in Alabama, Maryland, Rhode Island, Tennessee, Texas, Virginia, and Wyoming using SOC 21-1094 Community Health Workers and the following titles commonly used for community health workers: community health worker, peer health educator, peer specialist, peer support specialist, doula and promotor de salud. The fields retrieved included: job title, employer, and job ad URL. 
The job ad URLs were used to generate a unique identifier for each observation and retrieve the content of each job ad. The observations were deduplicated using the unique identifier; 20,050 duplicate observations were removed.

Employers were categorized by type as (1) hospitals/health systems, (2) other non-hospital healthcare, (3) health department, (4) health plans, (5) community-based organizations, (6) other, and (0) unknown. The observations with employer types other and unknown were removed to reduce false positive results for community health worker related job ads. The final sample includes 80,569 job ads. Table 2 and Table 3 display the distribution of ads by search term and state, respectively. Table 4 displays the distribution of ads by employer type and Table 5 displays the count of unique employers by employer type and state.

Table 2 Job Ads by Search Term

\begin{tabular}{|lll|}
\hline Search Term & Frequency & Percent \\
\hline BLS SOC 21-1094 & 47,820 & 59.35 \\
\hline community health worker & 12,692 & 15.75 \\
\hline doula & 76 & 0.09 \\
\hline peer health educator & 745 & 0.92 \\
\hline peer specialist & 8,919 & 11.07 \\
\hline peer support specialist & 10,316 & 12.80 \\
\hline promotor de salud & 1 & 0.00 \\
\hline Total & 80,569 & $100 *$ \\
\hline
\end{tabular}

Table 3 Count of Job Ads for Community Health Workers by State and Year

\begin{tabular}{|lllllll|}
\hline State Occupational Regulation & $\mathbf{2 0 1 7}$ & $\mathbf{2 0 1 8}$ & $\mathbf{2 0 1 9}$ & $\mathbf{2 0 2 0}$ & Total & Percent \\
\hline Alabama & 791 & 958 & 1,118 & 959 & 3,826 & 4.75 \\
\hline Pennsylvania & 7,497 & 4,478 & 6,481 & 1,761 & 20,217 & 25.09 \\
\hline Rhode Island & 514 & 808 & 648 & 698 & 2,668 & 3.31 \\
\hline Tennessee & 1,854 & 2,743 & 3,532 & 2,929 & 11,058 & 13.72 \\
\hline Texas & 5,435 & 6,837 & 7,262 & 7,162 & 26,696 & 33.13 \\
\hline Virginia & 2,884 & 2,913 & 4,027 & 5,170 & 14,994 & 18.61 \\
\hline Wyoming & 321 & 241 & 264 & 284 & 1,110 & 1.38 \\
\hline Total & 19,296 & 18,978 & 23,332 & 18,963 & 80,569 & 100 \\
\hline
\end{tabular}

Table 4 Count of Job Ads for Community Health Workers by Employer Type and State 


\begin{tabular}{|c|c|c|c|c|c|c|c|c|c|}
\hline Employer Type & $\mathrm{AL}$ & PA & $\mathbf{R I}$ & TN & $\mathrm{TX}$ & VA & WY & Total & Percent \\
\hline Hospital/health systems & 978 & 5,890 & 800 & 2,517 & 8,362 & 4,209 & 348 & 19,261 & 29.8 \\
\hline $\begin{array}{l}\text { Other non-hospital } \\
\text { healthcare }\end{array}$ & 813 & 2,860 & 319 & 893 & 2,471 & 2,051 & 194 & 7,701 & 11.9 \\
\hline Health department & 469 & 1,561 & 416 & 679 & 2,106 & 1,119 & 211 & 5,202 & 8.0 \\
\hline Health plans & 714 & 4,576 & 573 & 5,667 & 6,843 & 3,436 & 146 & 15,428 & 23.9 \\
\hline $\begin{array}{l}\text { Community-based } \\
\text { organizations }\end{array}$ & 853 & 5,330 & 560 & 1,306 & 6,914 & 4,179 & 211 & 16,983 & 26.3 \\
\hline Total & 3,827 & 20,217 & 2,668 & 11,062 & 26,696 & 14,994 & 1,110 & 64,575 & 100 \\
\hline
\end{tabular}

Table 5 Count of Unique Employer by Employer Type and State

\begin{tabular}{|llllllllll|}
\hline Employer Type & AL & PA & RI & TN & TX & VA & WY & Total & Percent \\
\hline Hospital/health systems & 116 & 502 & 61 & 255 & 790 & 517 & 52 & 2,293 & 16.6 \\
\hline Other non-hospital healthcare & 139 & 403 & 40 & 219 & 575 & 342 & 43 & 1,761 & 12.8 \\
\hline Health department & 5 & 22 & 7 & 3 & 19 & 33 & 1 & 90 & 0.7 \\
\hline Health plans & 57 & 712 & 58 & 93 & 926 & 700 & 11 & 2,557 & 18.5 \\
\hline Community-based organizations & 112 & 5331 & 87 & 208 & 684 & 603 & 31 & 7,056 & 51.1 \\
\hline Total & 429 & 6970 & 253 & 778 & 3044 & 2195 & 138 & 13,807 & 100 \\
\hline
\end{tabular}

Analysis of content involved use of Python and Beautiful Soup, to parse the content of the job ads, which were then analyzed using Natural Language Toolkit (NLTK) 3.6, to tokenize the language data and lemmatize key words for this analysis. We then developed a list of key words using roles, skills, and qualities for community health workers identified by the Community Health Worker Consensus Project (38). See Table 6 for the list of lemmatized key words. A binary variable was created for each lemmatized key word and assigned 0 if the ad did not include the word(s) or 1 if it included the word(s). A composite variable for skills, qualities, and roles was generated from the sum of values for individual key words under each category.

Table 6 Lemmatized Key Words for CHW Skills, Qualities, and Roles 


\begin{tabular}{|lll|}
\hline Skills & Qualities & Roles \\
\hline Assessment & Care & Advocate \\
\hline Communicate & Compassionate & Care coordination \\
\hline Community & Honest & Case management \\
\hline Evaluation & Motivate & Coach \\
\hline Facilitation & Patient & Cultural \\
\hline Health disparity & Reliable & Direct Service \\
\hline Outreach & Self-direct & Health education \\
\hline Professional & & Mediation \\
\hline Public health & & Social support \\
\hline Relationship building & & System navigation \\
\hline Social determinant & & \\
\hline Social service system & & \\
\hline
\end{tabular}

Finally, in the third phase of this study, we tested a series of hypotheses using one-way analysis of variance (ANOVA), chi-square analysis (CHI2), and multivariate ANOVA (MANOVA) to examine the association between state CHW regulation (policy) and CHW skills, qualities, and roles. The first ANOVA compares composite scores for skills, qualities, and roles between individual states. The second ANOVA compares composite scores for skills, qualities, and roles between state groups (i.e., no policy, new policy, and mature policy). A Bonferonni post-hoc analysis was conducted for the first and second ANOVA. The third analysis used chi-square analysis to test the association between state groups and individual key words representing CHW skills, qualities, and roles (e.g., assessment, care, advocate). The final of analyses used MANOVA, to address possible threats to validity, because the data were not normally distributed, and the sphericity assumption is often violated.

\section{Results}

Table 7 presents the descriptive statistics for the outcome variables. Descriptive statistics for the independent variables (i.e., states, state type, and employer type) were presented in Methods (Table 3 and Table 4).

Table 7 Descriptive Statistics for Outcome Variables 


\begin{tabular}{|c|c|c|c|}
\hline Variable & Obs & Mean & Std. Dev. \\
\hline \multicolumn{4}{|l|}{ Skills } \\
\hline Assessment & 80,556 & 0.42 & 0.49 \\
\hline Community & 80,556 & 0.92 & 0.27 \\
\hline Evaluation & 80,556 & 0.23 & 0.42 \\
\hline Facilitation & 80,556 & 0.03 & 0.18 \\
\hline Health disparity & 80,556 & 0 & 0.04 \\
\hline Outreach & 80,556 & 0.11 & 0.31 \\
\hline Professional & 80,556 & 0.6 & 0.49 \\
\hline Public health & 80,556 & 0.04 & 0.19 \\
\hline Social determinant & 80,556 & 0.01 & 0.09 \\
\hline Social service system & 80,556 & 0 & 0.05 \\
\hline \multicolumn{4}{|l|}{ Qualities } \\
\hline Care & 80,556 & 0.73 & 0.44 \\
\hline Compassionate & 80,556 & 0.07 & 0.26 \\
\hline Honest & 80,556 & 0.01 & 0.09 \\
\hline Motivate & 80,556 & 0.06 & 0.23 \\
\hline Patient & 80,556 & 0.43 & 0.5 \\
\hline Reliable & 80,556 & 0.12 & 0.32 \\
\hline Self-direct & 80,556 & 0.02 & 0.13 \\
\hline \multicolumn{4}{|l|}{ Roles } \\
\hline Advocate & 80,556 & 0.14 & 0.34 \\
\hline Care coordination & 80,556 & 0.05 & 0.21 \\
\hline Case management & 80,556 & 0.21 & 0.41 \\
\hline Coach & 80,556 & 0.12 & 0.33 \\
\hline Cultural & 80,556 & 0.14 & 0.35 \\
\hline Direct service & 80,556 & 0.03 & 0.18 \\
\hline Health education & 80,556 & 0.04 & 0.19 \\
\hline Mediation & 80,556 & 0.01 & 0.08 \\
\hline Social support & 80,556 & 0.02 & 0.14 \\
\hline System navigation & 80,556 & 0 & 0.03 \\
\hline
\end{tabular}

We used ANOVA to analyze and compare composite scores for skills, qualities, and roles between individual states. Among the key findings, the average number of job ads with roles $(F(6,80549)=109.43, p=0.000)$, skills $(F(6,80549)$ 
$=136.13, p=0.000)$, and qualities $(F(6,80549)=257.29, p=0.000)$ identified varied significantly between states. See Table 8.

We also observed that the average number of jobs ads with roles $(F(2,80553)=218.36, p=0.000)$, skills $(F(2,80553)=$ $274.78, p=0.000)$, and qualities $(F(2,80553)=634.91, p=0.000)$ identified varies significantly based on state type Table 9). Using a Bonferroni post hoc test, we found states without $\mathrm{CHW}$ policies were significantly different than states with new $\mathrm{CHW}$ policy $(p=0.000)$ and those with mature $\mathrm{CHW}$ policy $(p=0.000)$. The mean number of job ads with C3 defined roles identified were higher in states with new policies (PA, RI, and VA) and in the mature policy state (TX). The mean number of job ads was higher in the mature policy state compared to states with $\mathrm{CHW}$ certification policy and those with new certification processes that were in place five years or less. Interestingly, job ads for community health workers were less likely to include C3 defined skills in states without state CHW certification regulation. The greatest number of job ads including C3 qualities were found in the mature state.

The number of job ads with individual roles (e.g., advocate, care coordination), skills, and qualities identified in them varied significantly $(p \leq 0.05)$ by state policy type. Refer to results in Table 10, Table 11, and Table 12.

In states without state $\mathrm{CHW}$ regulation(s), the mean composite score for roles $(\mathrm{F}(4,15980)=228.55, p=0.000)$, skills $(F(4,15980)=86.79, p=0.000)$, and qualities $(F(4,15980)=634.23, p=0.000)$ varied significantly based on employer type. The mean composite score for roles and skills was highest in health plans and the mean score for qualities was highest in hospital/health systems, followed closely by non-hospital healthcare organizations and health plans. See Table 13. The Bonferroni post-hoc test for roles indicated the means were not significantly different between nonhospital healthcare employers and health departments; all other differences are significant $(p=0.000)$. For skills, the means were not significantly different between hospital/health system employers and Community-based Organizations, or non-hospital healthcare organizations and health departments. The means for qualities were not significantly difference between non-hospital healthcare employers and health plans.

The composite scores for roles, skills, and qualities also varied significantly by employer type in new and mature policy states. The mean scores for roles and skills were again highest in health plans and the mean score for qualities were highest in hospital/health systems. The results were statistically significant for all outcomes $(p=0.000)$. See Table 14 and Table 15. The results of the Bonferroni were not significantly different between hospital/health system and nonhospital healthcare employers for roles in new policy states; all other means were significantly different between employer types for roles, skills, and qualities. In mature states, the means for roles were not significantly different between hospital/healthcare employers and Community-based Organizations or Community-based Organizations and health departments; all others were significant $(p=0.000)$. The means for skills were not significantly different between non-hospital healthcare and health plans, but all others were significant $(p=0.000)$. The means for qualities were statistically different $(p=0.000)$ between employer types with the exception of health plans and CBOs.

MANOVA was utilized as an alternative test to ensure validity of test because of the limitation of ANOVA and its susceptibility to violations of the assumption of sphericity. From our analyses, we reject the null hypothesis that state occupational regulation type $(F(2,80553)=374.34), p=0.000)$ and employer type $(F(4,80551)=1111.21, p=0.000)$ have no effect on roles, skills, and qualities identified in job ads.

\section{Discussion}

$\mathrm{CHWs}$ represent an important resource for addressing the health of underserved communities. Employment of $\mathrm{CHW}$ is increasingly as a strategy to provide culturally competent care, address the social determinants of health, and improve access to health and social services for members of traditionally underserved communities. As the occupation

Page 10/16 
becomes more 'professionalized' through state regulatory mechanisms such as certification, we expect employers of $\mathrm{CHWs}$ to rely on the standards set by the state and professional organizations to ensure the entrants in the occupation are fully prepared to fulfill the obligations of their roles in a variety of organizational settings.

This research represents an important contribution to understanding the diffusion and adoption of occupational standards by employers. This study found employers in states with $\mathrm{CHW}$ certification programs were associated with greater adoption of the occupational roles and skills recommended by C3. Health plans type employers may have greater standardization in how $\mathrm{CHWs}$ are employed and therefore were more likely to have job ads that incorporated the specific terms we searched for (in the job ad analysis part of this study). Hospitals/health systems job ads were associated with a higher number of the $\mathrm{C} 3$ qualities. Given that $\mathrm{CHWs}$ and $\mathrm{CHW}$ programs are leveraged by health systems for their unique ability to connect with and understand members of communities outside the direct healthcare setting, this finding is not surprising. Adoption of a uniformed framework for regulation that specifies $\mathrm{CHW}$ roles, skills, and qualities needed to function across various states, organizations, and practice types may improve recognition of the workforce, reduce role confusion, and ensure that the unique skillset of CHWs is well understood by employers, policy makers and the public.

There are a few limitations in our study. The results from this study may not be generalizable given our purposive sampling of job ads from specific states. Additionally, there are important differences in how states regulate $\mathrm{CHWs.}$ These differences may affect employer behavior and influence the adoption of occupational standards set by state and national $\mathrm{CHW}$ associations. Future studies may consider how the differences in state-level regulation affect the professionalization of this occupation.

\section{Conclusions}

The CHW workforce will likely continue to grow as the Biden administration aims to improve care to those in underserved communities by adding 150,000 community health workers.(39) As the number of practicing CHWs grow and the adoption of $\mathrm{CHW}$ programs climb, a certain degree of professional regulation may be beneficial to establish standard indicators or definitions of $\mathrm{CHW}$ qualifications, gain recognition for $\mathrm{CHWs}$ as a profession, and/or meet financing requirements. Adoption of national or state established competencies by employers may also lead to improved employment stability, career paths, and resourcing for CHW services. $(40,41)$

\section{Abbreviations}

\section{AL Alabama}

ANOVA Analysis of Variance

C3 Community Health Workers Core Consensus Project

CDC Centers for Disease Control and Prevention

CHI2 chi-square

CHW Community Health Worker

COVID Coronavirus

DoL Department of Labor

Page $11 / 16$ 
MANOVA Multivariate Analysis of Variance

MCO Managed Care Organization

NLP Natural Language Processing

NLTK Natural Language Toolkit

PA Pennsylvania

RI Rhode Island

SOC standard occupation code

SPA State Plan Amendment

TN Tennessee

TX Texas

URL The address of a web page

VA Virginia

WY Wyoming

\section{Declarations}

Ethics approval and consent to participate. The George Mason University institutional review board determined this study to be exempt.

Consent for publication. Not applicable.

Availability of data and materials. The data that support the findings of this study are available from Chmura but restrictions to the availability of these data, which were used under license for the current study, and so are not publicly available. Data are however available from the authors upon reasonable request and with permission of Chmura.

\section{Competing interests.}

The authors declare that they have no competing interests.

\section{Funding.}

Funding for this research was provided by the Claude Moore Charitable Foundation. The Foundation was not involved in the study design; collection, analysis, or interpretation of data; or writing of the manuscript.

\section{Author's contributions.}

TJ developed the concept and design for the research, conducted interviews, conducted literature review, conducted data analysis and interpretation, and led the writing of the article. 
AS conducted background research, coordinated and participated interviews with stakeholders, and was a major contributor in writing the manuscript.

SR extracted data, conducted natural language processing, and conducted descriptive analysis.

MA extracted data, conducted natural language processing, and conducted descriptive analysis.

SR2 extracted data, conducted descriptive analysis, and was a contributor in writing the manuscript.

PM provided expertise in developing the concept for the research and was a contributor in writing the manuscript.

All authors read and approved the final manuscript.

\section{Acknowledgements.}

We recognize and thank the community health worker subject matter experts who participated in interviews with our team and provided expertise that guided this study. We also acknowledge Dr. Janusz Wojtusiak and Dr. Pangiota Kitsantis for providing expert guidance in methods used for natural language processing and statistical analysis. Additionally, Alexandria Greenlaw, provided assistance in coding state types.

\section{References}

1. Support for Community Health Worker Leadership in Determining Workforce Standards for Training and Credentialing [Internet]. [cited 2021 Apr 25]. Available from: https://www.apha.org/policies-and-advocacy/publichealth-policy-statements/policy-database/2015/01/28/14/15/support-for-community-health-worker-leadership

2. Kangovi S, Blackstock U. Opinion | Community health workers are essential in this crisis. We need more of them. Washington Post [Internet]. [cited 2021 Mar 30]; Available from:

https://www.washingtonpost.com/opinions/2020/07/03/community-health-workers-are-essential-this-crisis-weneed-more-them/

3. Health Educators and Community Health Workers: Occupational Outlook Handbook: : U.S. Bureau of Labor Statistics [Internet]. [cited 2021 Apr 13]. Available from: https://www.bls.gov/ooh/community-and-socialservice/health-educators.htm\#tab-6

4. Community Health Workers [Internet]. U.S. Bureau of Labor Statistics. [cited 2021 Apr 25]. Available from: https://www.bls.gov/oes/current/oes211094.htm

5. Community Health Worker National Workforce Study [Internet]. U.S. Department of Health and Human Services Health Resources and Services Administration; 2007 Mar [cited 2021 Mar 24]. Available from: https://bhw.hrsa.gov/sites/default/files/bureau-health-workforce/data-research/community-health-workforce.pdf

6. Fournier D, Rush C, Wilkinson G. Financing Strategies to Support the Community Health Worker (CHW) Workforce [Internet]. 2019 Nov 12 [cited 2021 Apr 27]. Available from: https://www.astho.org/Programs/Clinical-toCommunity-Connections/Documents/Overview-of-Financing-Strategies-to-Support-CHWs/

7. State Public Health Actions (1305) (2013-2018) I DNPAO | CDC [Internet]. 2020 [cited 2021 Apr 13]. Available from: https://www.cdc.gov/nccdphp/dnpao/state-local-programs/span-1807/past-program.html

8. Coronavirus Disease 2019 [Internet]. Centers for Disease Control and Prevention. 2021 [cited 2021 Apr 13]. Available from: https://www.cdc.gov/media/releases/2021/p0325-community-healthworkers-support.html

9. To Strengthen the Public Health Response To COVID-19, We Need Community Health Workers | Health Affairs Blog [Internet]. [cited 2021 Apr 13]. Available from:

Page 13/16 
https://www.healthaffairs.org/do/10.1377/hblog20200504.336184/full/

10. Bovbjerg RR, Eyster L, Ormond BA, Anderson T, Richardson E. Opportunities for Community Health Workers in the Era of Health Reform. :50.

11. Long JA, Jahnle EC, Richardson DM, Loewenstein G, Volpp KG. Peer mentoring and financial incentives to improve glucose control in African American veterans: a randomized trial. Ann Intern Med. 2012 Mar 20;156(6):416-24.

12. Heisler M, Vijan S, Makki F, Piette JD. Diabetes control with reciprocal peer support versus nurse care management: a randomized trial. Ann Intern Med. 2010 Oct 19;153(8):507-15.

13. Kim K, Choi JS, Choi E, Nieman CL, Joo JH, Lin FR, et al. Effects of Community-Based Health Worker Interventions to Improve Chronic Disease Management and Care Among Vulnerable Populations: A Systematic Review. American Journal of Public Health [Internet]. 2016 Apr [cited 2021 Mar 26];106(4):E3-28. Available from: http://search.proquest.com/docview/1776149852/abstract/C4A9ABE1EDAA4E81PQ/1

14. Viswanathan M, Kraschnewski JL, Nishikawa B, Morgan LC, Honeycutt AA, Thieda P, et al. Outcomes and Costs of Community Health Worker Interventions: A Systematic Review. Medical Care [Internet]. 2010 [cited 2021 Mar 26];48(9):792-808. Available from: http://www.jstor.org/stable/25750559

15. Addressing Chronic Disease through Community Health Workers: A Policy and Systems-Level Approach_April 2015. :27.

16. Chang A, Patberg E, Cueto V, Li H, Singh B, Kenya S, et al. Community Health Workers, Access to Care, and Service Utilization Among Florida Latinos: A Randomized Controlled Trial. Am J Public Health. 2018 Sep;108(9):1249-51.

17. Patient-Centered Community Health Worker Intervention to Improve Posthospital Outcomes: A Randomized Clinical Trial | Clinical Pharmacy and Pharmacology | JAMA Internal Medicine | JAMA Network [Internet]. [cited 2021 Apr 13]. Available from: https://jamanetwork.com/journals/jamainternalmedicine/fullarticle/1828743

18. Fisher EB, Strunk RC, Highstein GR, Kelley-Sykes R, Tarr KL, Trinkaus K, et al. A randomized controlled evaluation of the effect of community health workers on hospitalization for asthma: the asthma coach. Arch Pediatr Adolesc Med. 2009 Mar;163(3):225-32.

19. Kangovi S, Mitra N, Grande D, Huo H, Smith RA, Long JA. Community Health Worker Support for Disadvantaged Patients With Multiple Chronic Diseases: A Randomized Clinical Trial. Am J Public Health [Internet]. 2017 Aug 17 [cited 2021 Mar 30];107(10):1660-7. Available from: https://ajph.aphapublications.org/doi/abs/10.2105/AJPH.2017.303985

20. Jack HE, Arabadjis SD, Sun L, Sullivan EE, Phillips RS. Impact of Community Health Workers on Use of Healthcare Services in the United States: A Systematic Review. J Gen Intern Med. 2017 Mar;32(3):325-44.

21. Campbell JD, Brooks M, Hosokawa P, Robinson J, Song L, Krieger J. Community Health Worker Home Visits for Medicaid-Enrolled Children With Asthma: Effects on Asthma Outcomes and Costs. Am J Public Health. 2015 Nov;105(11):2366-72.

22. Kangovi S, Mitra N, Norton L, Harte R, Zhao X, Carter T, et al. Effect of Community Health Worker Support on Clinical Outcomes of Low-Income Patients Across Primary Care Facilities: A Randomized Clinical Trial. JAMA Intern Med. 2018 Dec 1;178(12):1635-43.

23. Policy Evidence Assessment Report: Community Health Worker Policy Components. 2014 Apr;13.

24. Community Health Workers: Evidence of Their Effectiveness. :2.

25. Kangovi S, Mitra N, Grande D, Long JA, Asch DA. Evidence-Based Community Health Worker Program Addresses Unmet Social Needs And Generates Positive Return On Investment. Health Affairs [Internet]. 2020 Feb 1 [cited 2021 Mar 30];39(2):207-13. Available from: https://www.healthaffairs.org/doi/full/10.1377/hlthaff.2019.00981 
26. Support for Community Health Workers to Increase Health Access and to Reduce Health Inequities [Internet]. [cited 2021 Apr 13]. Available from: https://www.apha.org/policies-and-advocacy/public-health-policy-

statements/policy-database/2014/07/09/14/19/support-for-community-health-workers-to-increase-health-accessand-to-reduce-health-inequities

27. What Evidence Supports State Laws to Establish Community Health Worker Scope of Practice and Certification? :14.

28. Community Health Worker Certification and Financing [Internet]. Association of State and Territorial Health Officials; 2016. Available from: https://www.astho.org/Community-Health-Workers/CHW-Certification-Financing/

29. State Community Health Worker Models - The National Academy for State Health Policy [Internet]. [cited 2021 Mar 26]. Available from: https://www.nashp.org/state-community-health-worker-models/

30. Malcarney M-B, Pittman P, Quigley L, Horton K, Seiler N. The Changing Roles of Community Health Workers. Health services research [Internet]. 2017 Feb [cited 2021 Mar 24];52 Suppl 1:360-82. Available from:

http://mutex.gmu.edu/login?url=http://search.ebscohost.com/login.aspx?

direct $=$ true $\& d b=m n h \& A N=28127766 \&$ site $=$ ehost-live

31. Arvey SR, Fernandez ME. Identifying the core elements of effective community health worker programs: a research agenda. Am J Public Health. 2012 Sep;102(9):1633-7.

32. Ibe CA, Wilson LM, Brodine J, Monroe D, Boonyasai RT, Meza B, et al. Impact of Community Health Worker Certification on Workforce and Service Delivery for Asthma and Other Selected Chronic Diseases [Internet]. Rockville (MD): Agency for Healthcare Research and Quality (US); 2020 [cited 2021 Mar 26]. (AHRQ Comparative Effectiveness Technical Briefs). Available from: http://www.ncbi.nlm.nih.gov/books/NBK555582/

33. State Public Health | ASTHO [Internet]. [cited 2021 Apr 25]. Available from: https://www.astho.org/StatePublicHealth/A-Patchwork-Quilt-of-State-Approaches-to-CHW-Training/05-30-19/

34. Texas Community Health Worker Study Report to the Texas Legislature [Internet]. Department of Health and Human Services; 2012 [cited 2021 May 1]. Available from: https://www.dshs.texas.gov/mch/pdf/Community_Health_Worker_Study_Report_Final.doc

35. Alexander-Scott N, Garneau D, Dunklee B. Community Health Workers in Rhode Island: Growing a public health workforce for a healthier state. 2018;119.

36. Mcallister V. Community Health Workers in Virginia. 2019.

37. Covey L, Hickey K, Deaner L, Lomax E, Ford N, Osborne S, et al. Pennsylvania Certification Board: Certified Community Health Worker. 2019 p. 7.

38. Roles \& Competencies [Internet]. CHW Core Consensus Project. 2018 [cited 2021 Apr 19]. Available from: https://www.c3project.org/roles-competencies

39. The Biden Plan for Mobilizing American Talent and Heart to Create a 21st Century Caregiving and Education Workforce [Internet]. Joe Biden for President: Official Campaign Website. [cited 2021 Apr 14]. Available from: https://joebiden.com/caregiving/

40. London K, Carey M, Russell K. Community Health Worker Certification Requirements by State. :10.

41. Dower C, Knox M, Lindler V, O’Neil E. Advancing Community Health Worker Practice and Utilization: The Focus on Financing. :89.

\section{Tables}

Due to technical limitations, table 8 to 15 is only available as a download in the Supplemental Files section. 


\section{Supplementary Files}

This is a list of supplementary files associated with this preprint. Click to download.

- Table8to15.docx 